\title{
RITUALES DE MACHI Y SUBVERSIONES DE GÉNERO EN LA
} POESÍA MAPUCHE ACTUAL

MACHI RITUALS AND SUBVERSION OF GENDER IN MAPUCHE CURRENT POETRY

\section{RESUMEN:}

Este artículo indaga desde la diferencia cultural otras ontologías de sexo y género que cuestionan las dicotomías binarias excluyentes de la modernidad eurocentrada para ello se analizan poemas de Adriana Paredes Pinda (2005), poeta y machi (chamán) del pueblo mapuche-williche, en el sur de Chile. La autora pone en juego prácticas corporales y cognitivas basadas en principios duales y complementarios, propias de un normativo de que resisten el sistema hetero(Judith Butler, 1998; Beatriz Preciado, 2011) liberando producciones de subjetividad (Felix Guattari, 1996) in-validadas históricamente por diversos dispositivos de saber-poder (Foucault, 1998) de la modernidad colonial.

(Foucault, 1998) de

Palabras claves:

Palabras Claves:
Género, diferencia cultural, poesía, $\begin{aligned} & \text { Gender, difference culturally, poetry, } \\ & \text { decoloniality. }\end{aligned}$

decolonialidad.
Abstract:

This article explores the cultural difference rom other ontologies of sex and gender questioning exclusionary binary dichotomies of European modernity, for it analyzed Adriana Paredes Pinda poems (2005), poet and machi (shaman) of the Mapuche- Williche people in southern Chile. The author bring into play physical and cognitive practices based on dual and complementary, a normative gender binary system exclusive Judith Butler, 1998; Beatriz Preciado, 2011) releasing productions of subjectivity (Felix Guattari, 1996) in-validated historically by various devices power-knowledge (Foucautt, 1998) of colonial modernity. Mapuche own ethos, which resist the hetero-

\section{LA POESÍA MAPUCHE ACTUAL Y SU AGENCIA POLÍTICA}

La poesía mapuche contemporánea se extiende a un lado y a otro de las fronteras en el sur de Chile y Argentina; se trata de una producción de diferencia cultural (Gilles Deleuze, Felix Guattari, 2002) que excede los límites de las literaturas nacionales monolingües de ambas naciones modernas. Una comunidad poética cuyos entramados y actos simbólicos tampoco son ajenos a los procesos de resistencia y reconfiguración política que el pueblo mapuche viene realizando en el contexto de los diversos conflictos interculturales y territoriales con las sociedades y modos de explotación hegemónicos.

Entre sus principales rasgos de diferencia hacemos notar su realización bilingüe, en castellano-mapuzungun y, especialmente, la identidad de sus poetas que se autoreconocen mapuche (gente de la tierra) o en algunas de sus identidades territoriales ${ }^{1}$, antes que chilenos o argentinos. Se trata de agentes de una práctica artístico-discursiva que libera subjetividades, memorias y epistemes de diferencia cultural y lingüística (Sergio Mansilla Torres; 2002; Fernanda Moraga, 2009).

En este contexto, creemos que la poesía de autores y autoras mapuche ${ }^{2}$, invariablemente entrelazada a los conflictos que suscita su situación de subalternidad colonial, interrumpe las continuidades teóricas y clasificatorias de la modernidad y cuestiona algunas "síntesis fabricadas" que deben revisarse y cuestionarse:

Estas formas previas de continuidad, todas esas síntesis que no problematizamos y que dejamos en pleno derecho, es preciso tenerlas, por lo tanto, en suspenso. No recusarlas definitivamente. Sino sacudir la quietud con la cual se las acepta; mostrar que no se deducen naturalmente, sino que son siempre el efecto de una construcción cuyas reglas se trata de conocer y cuyas justificaciones hay que controlar. (Foucault 1979: 41)

Cualquier tipo de clasificación de esta poesía dentro de nuestras habituadas zonas conceptuales de lo literario será incómoda, incompleta, a la vez que necesaria para repensar o poner en crisis los estatutos estético culturales hegemónicos ya que, como práctica artística intercultural, contiene campos de representación intra-culturales en tanto que aborda y transfigura elementos de la antigua cultura oral mapuche pero, a la vez, realiza una apropiación conflictiva en diálogo con la poesía moderna y sus cánones (Iván Carrasco, 2000).

1 El pueblo mapuche se reconoce en la actualidad en ese pan-gentilicio, sin excluir sus diversidades territoriales, culturales, lingüísticas a ambos lados de la Cordillera de los Andes como los willich (gente de sur), puelche (gente del oeste), pehuenche (gente del pehuén), picunche (gente del norte) lafkenche (gente del bordemar), entre otras parcialidades.

2 No usamos la forma castellanizada del plural "mapuches", respetando la no utilización de ese morfema de número dentro de palabra en mapuzungun, la lengua mapuche. Los plurales en esta lengua se hacen con el morfema "pu", fuera de palabra, existiendo también formas pronominales que distinguen el número "dual", distinción que no existe en español. 
Las y los poetas mapuche actuales ya no expresan, como dice la propia Adriana Paredes Pinda, "un universo idéntico en sí" (2005:08), no constituyen la voz de los antiguos nguenpin ${ }^{3}$, orador tradicional, literalmente: "dueño de la palabra", hablando de un universo representacional antiguo, "esencial" o para sí. Por lo contario, expresan su situación actual de conflicto con el otro y con ellos mismos como sujetos culturales. “La cultura escritural nos convierte en desolados y desoladas, nos hace herederos de su imperialismo discursivo de su poder simbólico y nos desarmamos, estoy enferma posesa por el weküfe $e^{4}$ de la escritura", (2005:09) escribe Paredes Pinda en el prólogo de su libro $\ddot{U} i$, dejando constancia de ese acto simultáneo de desgarro y apropiación cultural.

En algunos casos, como en las producciones de Paredes Pinda, el poema se abre a una performatividad de múltiples voces y memorias que escenifican una conciencia colectiva; otras veces, el poema es transfigurado por antiguas formas orales y retóricas del mapuzungun, como los pentukun, los epew, las nütram, e incluso por cantos ceremoniales como el tayül $l^{5}$ y otras formas de éxtasis y usos rituales del lenguaje, antiguamente reservados a oradores específicos como $\mathrm{pu} \mathrm{machi}^{6}$ en contextos sagrados (Jorge Spíndola, 2009).

\section{LA OPCIÓN DECOLONIAL E INTERCULTURAL}

Uno de los fundamentos de los estudios decoloniales en América del Sur radica en la imposibilidad de pensar la existencia y configuración de la modernidad en nuestras regiones sin su contraparte colonial y sus consecuencias más extensas y duraderas en prácticas y subjetividades, esto es: la colonialidad del poder, del saber y del ser (Aníbal Quijano, 2003). Nuestra perspectiva está focalizada en el análisis de la colonialidad del saber, ésta cuestiona la pretensión eurocéntrica de producir un saber "universal",

3 Las traducciones de palabras y frases del mapuzungun son propias. Se realizan inmediatamente después de palabra o frase en mapuzungun, ya sea entre paréntesis o como aposición para agiliza su comprensión. En el caso de las traducciones de palabras que están dentro de los textos de Paredes Pinda, hemos preferido una nota al pie para no intervenir dentro del corpus. Las escrituras de una misma palabra en mapuzungun presentan diferencias que se deben a variantes regionales de habla y a la utilización de distintos grafemarios debido a que en su tránsito de la oralidad a la escritura aún no hay un consenso definitivo acerca de su representación gráfica.

4 Weküfe: ente maligno.

5 Tanto el pentukun (discurso de saludo), como los epew (relatos), las nütram (conversaciones y relatos acerca de historias "verdaderas"), integran formas discursivas propias de la cultura mapuche oral. El tayül es una versión sagrada de los ül, cantos (con o sin acompañamiento de instrumento musicales) cuya realización más cotidiana y menos ritualizada es conocida como "romancear" entre
las comunidades mapuche del Puel Mapu (Argentina). Para un mayor acercamiento recomendamos las comunidades mapuche del Puel Mapu (Argentina). Para un mayor acercamiento recomendamos Lucía Golluscio.2006. El pueblo mapuche poéticas de pertenencia y devenir. Editorial Biblos, Buenos Aires.

6 Para referirnos a la figura de machi en plural utilizaremos el artículo "pu", propio del mapuzungun, ya que éste no distingue género como los artículos "las" o "los" del castellano, con implicancias que más adelante analizaremos. "objetivo", distanciado de sí, no situacional, desde un punto de vista que subsume todos los puntos de vista pero que no aparece como tal. Según Santiago Castro Gómez (2003) se trataría de un conocimiento producto de un sujeto que se imagina en capacidad de poseer una "mirada de dios" que lo ve todo, pero que no puede ser visto, que está por encima observando lo existente de forma omnipresente y omnisciente. La supuesta universalidad de ese saber se apoyaría también en la creencia de un sujeto que se atribuye la categoría final de "Hombre", representante de los alcances evolutivos finales de "la humanidad". Desde esta perspectiva crítica se afirma que la colonialidad del saber debe ser entendida como la represión de otras formas de producción del conocimiento (que no sean blancas, europeas y "científicas"), negando el legado intelectual de pueblos "indígenas" o "negros", reduciéndolos como primitivos a partir de la categoría básica y naturalizada de "raza", fijando sus saberes e identidades en un pasado no "in-corpo-rable" a la modernidad.

Desdeesta opción por la decolonización del saber, proponemos para nuestras lecturas una crítica intercultural históricamente situada, reconociendo la pertinencia y validez epistemológica del rakizuam mapuche -pensamiento mapuche- para comprender el mundo que pone en juego esta poesía. Por otra parte estableceremos un diálogo con la teoría de la performatividad de Judith Butler y otros estudios que cuestionan el orden hetero-normativo europeo/americano que se sostiene en la subordinación general de las mujeres al patriarcado (Robert W. Connell, 1997). El trabajo de traducción intercultural que implica este tipo de análisis se realiza en base a estudios de la lingüista mapuche María Catrileo (2011) y trabajos etnográficos de la antropóloga chilena Ana Mariella Bacigalupo $(2003,2004,2010)$, además de saberes propios del mundo y la literatura mapuche-williche.

\section{LA FIGURA DE MACHI Y EL PENSAMIENTO DUAL COMPLEMENTARIO MA-} PUCHE

Ukuy ima qhari warmi (todo es hombre y mujer)

-Frase popular en lengua quechua-

$P u$ machi, chamanes y agentes cosmovisionales de la cultura mapuche tradicional, cumplen roles de sanación y espiritualidad aún vigentes y en continúa reelaboración en el contexto general arriba descripto. Sus prácticas concitan vínculos de cohesión comunitaria basadas en el küifi rakizuam, el antiguo saber y hacer mapuche, que incluye un alto grado de conocimiento de medicinas elaboradas en base a la herboristería nativa (lawen), poderes de éxtasis y de posesión espiritual como el vuelo mágico durante estados especiales de conciencia (kuymi) que les permiten la visión (pelontün) y comprensión de las enfermedades desde un ethos cultural propio, donde la salud de la persona ( $a z$ che) está íntimamente articulada a una noción de orden cosmológico y social. 
Los roles religioso- políticos y de sanación de pu machi, sometidos a la devastadora presión colonial y la persistente colonialidad, han variado significativamente. Enalgunas regiones el contacto desigual con el catolicismo y luego el cristianismo pentecostal han dejado profundas huellas de diglosia en los signos de lo sagrado ${ }^{7}$. Como agentes cosmovisionales sus prácticas tradicionales están en una continua reelaboración aunque siempre ligada a los rasgos simbólicos de la sociedad mapuche con el mundo sagrado; una relación holística y variable que incluye el vínculo con los antepasados, la naturaleza, los animales, la tierra, las relaciones humanas intra e interculturales, entre otras razones que explican, por ejemplo, la resistencia sacralizada ante los desastres ambientales provocados por las compañías forestales o los emprendimientos hidroeléctricos trasnacionales en territorios ancestrales.

Una de las cualidades de pu machi, en tanto agentes cosmovisionales, es concentrar sobre sí esos elementos nucleares o configuradores de la antigua cultura, uno de ellos (que aquí focalizamos especialmente) es la práctica simbólica del pensamiento dual y complementario que aún persiste en la sintaxis verbal y pronominal del mapuzungun ${ }^{8}$ y que participa de su "performatividad ritual" (Bacigalupo, 2010: 84), como luego veremos.

Junto con la lingüista mapuche María Catrileo entendemos que "los hechos lingüísticos son culturales y están determinados culturalmente" (2011: 63), por ello hacemos visible que la noción de "género" en mapuzungun no tiene representación en morfemas como ocurre en el español, otorgando así una plasticidad cultural a verbos y sustantivos (acciones y sujetos) que es necesario comprender desde una complejidad psíquica y cultural necesariamente distinta al sistema binario de género excluyente y colonial:

Por ejemplo, la representación de cargos de liderazgo en una antigua comunidad rural no se realiza pensando en lo masculino y femenino, considerando al sexo como un sentimiento de valor. Es más la unión pronominal de tipo Lautaro o Guacolda que funciona en la tradición y pensamiento cultural y no como un concepto verbal que distingue entre masculino y femenino. De este modo el cargo de Longko (jefe) puede referirse a un hombre o a una mujer sin hacer esta referencia específica a través de la lengua. (Catrileo, 2011: 64)

La gramática española -como otras lenguas indoeuropeas- define el "género" como una categoría que clasifica sustantivos y pronombres en clases opositivas en referencia al sexo. El mapuzungun, en cambio, se refiere a "él" o "ella" sin distinción con un mismo pronombre: fey. El sexo natural o biológico es "una categoría de tipo

7 Estas tensiones y convergencias entre la ritualidad williche y el culto cristiano pentecostal han sido ampliamente estudiadas por el antropólogo Rodrigo Moulian Tesmer. 2011. Metamorfosis Ritual ampliamente estudiadas por el antropólogo Rodrigo Moulian Tesmer. 20

8 Pronombres duales del mapuzungun: iñchiw: nosotros dos/ eymu: ustedes dos/ fey engu: ellos dos. nocional" (Catrileo, 2011: 64) en que domo (mujer) y ülcha (mujer joven) se distinguen del sexo biológico de wentrü (hombre) y alka (gallo), sólo cuando hay una exigencia de desambiguación que no otorga el contexto. Por ejemplo: narqui: indistintamente gato o gata - wentrü narqui: gato. Ufisha: oveja o carnero indistintamente - alka ufisha: cordero o carnero. Domo ufisha: oveja.

Estas diferencias en las nociones de lo dual que permean con una plasticidad cultural propia las actuaciones de lo masculino y lo femenino del mundo mapuche, han sido pieza de conflicto y malentendidos -no sólo lingüísticos- desde los primeros contactos con la lógica y el tabú colonial del sexo-género binario y opositivo. La deidad mapuche por excelencia es la entidad cuatripartita llamada Ngenechen, representa en sí misma la dualidad opuesta y complementaria de todo lo viviente: Wenü Fücha (anciano del cielo), Wenü Kushe (anciana del cielo), Wenü Weche (joven varón del cielo) y Wenu Ülcha (joven mujer del cielo). Estos ancestros del Wenü Maри (tierra de arriba), entre otros atributos reúnen en su unidad nociones generacionales como juventud y vejez, fuerza y sabiduría (newen y kimün), fertilidad y guerra, y también se convierten en un espacio de transfiguración simbólica de las nociones occidentales opositivas de género del tipo hombre-mujer. La antropóloga chilena Ana María Bacigalupo, siguiendo a Judith Butler ha realizado estudios críticos con base etnográfica respecto de esas representaciones de género dual en la performatividad ritual de pu machi:

\section{La perturbación o trasgresión de normas morales o sociales y el incumplimiento de compromisos con espíritus de ancestros y con la deidad mapuche Ngünechen producen enfermedad social así como el caos. A fin de ayudar a prevenir o reparar tales perturbaciones, los machi utilizan categorías generacionales y de género -la variedad de atributos y predisposiciones considerados femeninos y masculinos- para vincular los mundos humanos con las realidades espirituales. Al imitar y manipular el género y categorías generacionales inherentes a la deidad cuatripartita Ngünechen, los machi liberan poderes cósmicos en un effuerzo por convertir la enfermedad, en (Bacigalupo 2004: 10)}

Las actuaciones del género dual adquieren diversas formas de representación por parte de pu machi según su creatividad y contexto socio-territorial. Algunas de esas dualidades son actuadas por las duplas machi-dungümachife (intérprete de machi que traduce su lenguaje en trance), machi-animal espiritual, se trata de la unión espiritual con un animal a través del aliento, el sudor o la sangre a fin de extender el poder y la cualidad relacional de pu machi con otras entidades del mundo. Los animales espirituales suelen ser caballos, toros, aves pero también animales totémicos como el pangui (puma), o el manke (cóndor). Así, el "yo" de pu machi se presenta como una entidad dialogante, no fija, un borde por el que fluye lo indeterminado. Este "devenir animal" es una de las 
diversas formas de la "multiplicidad simbiótica y hetero-genérica" (Deleuze y Guattari 2002: 136) con la que pu machi se asumen como entes dialogantes-colectivos.

La performatividad ritual de género dual y complementario de pu machi, también llamada matrimonio espiritual por Bacigalupo (2010: 85) alcanza su momento de mayor fluidez y poder en el trance cuando son poseídos o poseídas por un espíritu (filew o pullï) al que deben seducir cualquiera sea su condición sexual biológica:

\section{Los machi masculinos y femeninos se convierten en novias espirituales para seducir y convocar a sus filew - esposo y dueño a la vez - para que posean sus cabezas y les otorguen conocimiento luciendo símbolos de femineidad y de condición de esposa: pañuelos de cabeza azules o violetas, collares de flores de kopiwe rojas y hojas de llankalawen, chales negros de mujer y alhajas de plata. El esposo filew está interesado en la performatividad de la condición de esposa y no en el sexo debajo de la vestimenta de la machi. El transvestismo ritual de los machi masculinos no trasciende las categorías de hombre y mujer sino que llama la atención sobre las categorías relacionales de género del esposo espiritual y esposa machi como pareja (kurewen). (Bacigalupo 2010: 86)}

La corporeidad ritual de pu machi, vinculada a esa performatividad de género aleatoria, dual y complementaria, pone en juego de forma disidente y subversiva la noción de género binaria excluyente "hetero-normativa" (Butler, 1998: 304), quizás por ello sea una de las menos comprendidas y más repudiadas (sobre todo la corporeidad de los machi biológicamente masculinos), primero por los conquistadores españoles y luego por nuestras prácticas permeadas de esa normatividad colonial. Son numerosos los registros de las persecuciones que van desde las acusaciones de brujería o posesiones demoníacas en la época colonial, pasando por las acusaciones de perversión sexual o ejercicio ilegal de la medicina, hasta las recientes imputaciones de terrorismo por la explícita defensa territorial de sus espacios ceremoniales comunitarios en el actual contexto global neoliberal.

Tal focalización selectiva en la persecución de estas corporeidades y sus prácticas culturales se harían más nítidas a través de una arqueología que indagara en los dispositivos de sexualidad (Foucault, 1998) y de racialidad (Quijano, 2003) que fueron penetrando el cuerpo material y simbólico-colectivo de la cultura mapuche; así como las relaciones de disputa entre esas formas modernas de represión y control biopolítico y las subversiones-resistencias de estos agentes cosmovisionales. La poesía de la machi Adriana Paredes Pinda, con su capacidad metafórica y testimonial nos alivie, por el momento, de ese trabajo de archivo foucaultiano más extenso.

\section{FILIPA HUENULEO: ESCENA 1}

\section{(UNA PERSECUCIÓN DE CUERPOS Y SABERES)}

¿Quién habla y quién actúa?

Siempre es una multiplicidad

incluso en la persona que habla o actúa.

Gilles Deleuze (Foucault, 2000:08)

La pluralidad de memorias y registros en la poesía de Paredes Pinda se presenta en forma de escenas discursivas donde actúan diversas voces y prácticas corporales que emergen y convierten al texto en un escenario colectivo, ya sea girando alrededor del rewe (árbol sagrado, axis mundi, lugar ceremonial de machi) o en la imantación de voces y de "otros", propia del estado de trance de machi. Más que una hablante lírica lo que hay es una multiplicidad, más que representación hay actos, puesta en escena de una performatividad que desaloja o interrumpe escrituras de saber- poder colonial sobre los cuerpos y las formaciones de subjetividad mapuche. Críticos como Claudia Rodríguez Monarca (2005) han visto en la figura de la machi mujer, asumida por poetas mapuche como Paredes Pinda, un "carácter intracultural" al reponer simbólicamente prácticas de salud y de trascendencia espiritual, a diferencia de un rol mediador o parlamentador (wepüfe) con la otredad cultural, asumido por poetas hombres. Desde nuestras lecturas proponemos visualizar también el carácter intercultural y decolonial de estas acciones poético-discursivas concentradas en la figura de machi, tales como las reposiciones en palimpsesto de cuerpos, voces, modos cognitivos borrados o invalidados por la religiosidad, la ciencia, la cárcel, el hospicio, entre otras formas de violencia.

Paredes Pinda trae a escena la voz-memoria de su antepasada Filipa Huenuleo, antigua machi perseguida y desalojada del territorio williche en el período posreduccional chileno tras la derrota militar y territorial conocida como Pacificación de la Araucanía:

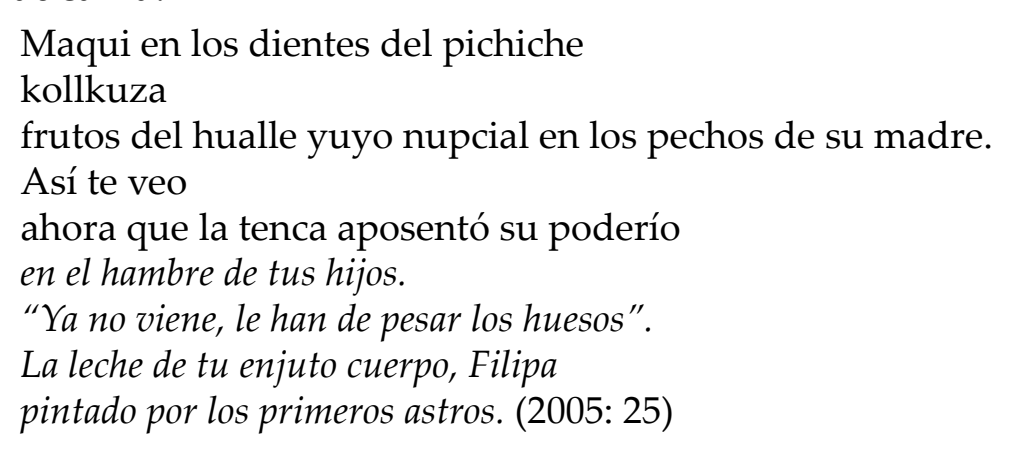

La leche ausente de Filipa Huenuleo es la de un cuerpo "pintado por los primeros astros", metáfora de antiguos relatos que hablan de un origen ligado a las estrellas. Las imágenes de Filipa están ligadas a una fertilidad femenina ahora ausente, rememorada en el murmullo creciente de voces que testimonian su poder de sanación: “Esa donde ponía las manos/ ponía la sanidad. Con mirarte/ sabía al tiro si bien o mal te habían hecho" (2005:25). Ya en los versos siguientes emerge esa dualidad complementaria de género que mencionábamos arriba:

Montó en los caballos ebrios de la guerra

Filipa Huenuleo. Las cabezas blancas 
quemaron la paja de sus sueños febriles.

Muchos como tú quedáronse

desnudos

en medio de su tierra ardiendo. (2005: 25)

Tras esa primera imagen de fertilidad ausente y deseada, emerge ésta otra, cas mítica, de Filipa montada "en los caballos ebrios de la guerra", revelando la condición de guerrero espiritual -atributo masculino- de $p u$ machi:

Mientras que la condición del estatus de machi novia refleja formas sutiles de accionar mediante las cuales los machi ganan conocimiento a través de la seducción femenina, la destreza ecuestre es una relación espiritual que implica una jerarquía y dominio explícitos sobre los espíritus y está asociada a la masculinidad y la guerra. La destreza ecuestre, montar y el dominio sobre los animales son símbolos de masculinidad, fortaleza, agilidad y prestigio para los machi, tal como eran para los guerreros mapuche y españoles de tiempos coloniales que se enfrentaron entre os siglos XVI y fines del XIX. (Bacigalupo 2010: 84)

Para Bacigalupo la "performatividad de género dual" permite que -indistintamente de su sexo biológico- $p u$ machi, como guerreros masculinos montados, derroten a los espíritus maléficos y a la extranjeridad colonial (léase aquí a "las cabezas blancas/ que quemaron la paja de sus sueños febriles", en los versos de Adriana Paredes Pinda). En este caso la poeta-machi pone en escena una segunda actuación de esa dualidad complementaria: Filipa Huenuelo ha sido desalojada del territorio, es un cuerpo enjuto, despojado y desnudo "en medio de su tierra ardiendo", sin embargo regresa en visones, montada como los antiguos guerreros masculinos. Este juego de imágenes dobles, de oposiciones que no se excluyen y se sostienen mutuamente sin reducirse a "lo uno" (como en el modelo cognitivo hegeliano de tesis-antítesis: síntesis) tendría como base ontológica esa dualidad complementaria propia del ethos cultural mapuche; una estrategia político- discursiva presente también en otros de sus acto-poemas (Spíndola 2009).

La escena de Filipa finaliza con un soliloquio en mapuzungun-español; la antigua machi habla de sus visiones premonitorias, sangran los cueros del kulltrung, el instrumento sagrado de pu machi donde se representa el Wall Mapu, el territorio mapuche:

Amutuan iñche amutuan"- no tengo/ ya mi hogar cantaba/ sangran de pena los cueros de tu Kultrúng/Huenuleo. Las blancas cabezas vinieron otra vez/ robarse las montañas. Hay que irse/ puro arrancar siempre de la tierra de una/ los guerreros mataron las blancas cabezas/ -Amutuan iñche, nielan ruka feula. / Filipa Huenuleo piñgen. Nielan Kvtralwe. Amutuan/ nomen tu lafken amutuan. / A la muerte me voy montada/ a la muerte/ en el lomo de nuestra oscuridad (2005: 24-25)
Estos últimos versos en mapuzungun, que marcan de forma conmovedora la salida de escena de Filipa pueden traducirse así: "Me iré, ahora ya no tengo casa/ Filipa Huenuleo es mi nombre/ No tengo hogar, me iré/ al otro lado del mar me iré" "otro lado del mar" hace referencia a la región o morada de los muertos, para las comunidades williche y lafkenche del sur de Chile.

\section{MERCEDES MILLAPAN. ESCENA 2}

\section{(UNA EXCARCELACIÓN DE CUERPOS Y SABERES}

El vocerío ahora nos habla de la antigua "hechicera" Mercedes Millapan, machi envuelta en un ritual de éxtasis que despierta la sensualidad de la naturaleza: los vientos y los pumas "amancebados" rondan su cuerpo en el rewe ceremonial en awun, la danza ritual que consiste en giros circulares, contrarios a los agujas del reloj, en favor de la rotación del eje de la tierra alrededor del sol:

los pumas
andan
rondando
como treiles
los atauleros
amancebados
por la temprananza de la lluvia
ah, sórdidos
los huracanes de la sangre
el embrión de piedra de las constelacio
fouchakemogen kemukemu ${ }^{10}$
(...)
los cometas de la bienaventuranza
murmuran
puigua hembra
al encuentro del mar (2005: 29)

al encuentro del mar (2005: 29)

La acción, nuevamente, ocurre en el centro del rewe, el "kemukemu", donde viven los espíritus antiguos; sólo que esta vez las fuerzas de lo numinoso buscan en el cuerpo "virgen" el "embrión" que lo une a las constelaciones. El estado de amancebamiento sexualiza a toda la naturaleza, hay un erotismo focalizado en la femineidad del mundo, el viento "puigua" es "hembra", por ejemplo. En este contexto de devenir sensual de la machi de pronto emerge con violencia la memoria de otro ritual, cuyo signo es la "hostia" cristiana:

9 La traducción es nuestra:

Amutuan iñche, nielan ruka feula Me iré, ahora ya no tengo casa

Filipa Huenuleo piñgen Filipa Huenuleo es mi nombre

Nielan Kvtralwe. Amutuan No tengo fogón (u hogar), me irè

nomen tu lafken amutuan. al otro lado del mar me iré

10 fvuchakemogen kemukemu: los antiguos padres viven en el rewue. (Traducción nuestra). 


\section{mientras}

que

ardiendo

su fuego

su fuego

despedazada por los prematuros

ha convocado

a conjurarnos de cóndores

a conjurarnos de cóndores

Se produce un juego de confrontaciones rituales y semióticas en el que debemos detenernos un momento si queremos comprender su dimensión política-decolonial La "hostia", un signo ajeno al rewe antiguo, metáfora del dios- otro (cuerpo del Cristo encarnado en el "Hombre"), es despedazada por "los prematuros" (los dioses más antiguos) en un conjuro de cóndores y de visones de la propia machi Pinda, que asume la voz y vela por el cuerpo de Millapi: un cuerpo performativamente femenino en el centro de la escena, desregulado de la penetración sexual eurocéntrica, una "hechicera" abriéndose a la sensualidad desatada por otro absoluto (no cristiano): su devenir con las fuerzas naturales articuladas desde la racionalidad holística del rewe mapuche.

El machi dungün, discurso de machi, está a cargo de Pinda quien monta los caballos de la guerra: "kawellu yea wiraftuga kawellu" (p. 31) (iyea caballos, vuelvan a girar, troten alrededor caballos, corran!); esta dualidad del ritual que reúne fertilidad y guerra dice relación con la performatividad de género dual donde "las machi pasan de ser mujeres (femeninas) cuando curan, a ser mujeres (masculinas) cuando realizan exorcismos y matan espíritus maléficos, weküfe" (Bacigalupo, 2003: 37).

El ritual de raspaje ${ }^{11}$ del dios cristiano sobre el cuerpo de Mercedes Millapán se completa implorando fuerzas de la naturaleza como el Volcán Llaima (en constante erupción desde el 2000), los vientos "puigua", los pájaros. Sólo cuando se ha desalojado simbólicamente a ese dios-otro del centro del rewe, se consuman los actos erótico-cognitivos, propios de machi. Las visiones restituyen imágenes de esa dualidad sexuada y complementaria, ahora encarnada en agentes naturales como los vientos: "puigua macho y puigua hembra" que soplan sobre los frutos fértiles "gargalas/ digüene/ kolkopío"12 y sobre el cuerpo de Millapan, pintado de rojo, "quelwe". Las mazorcas fálicas van desmenuzando las caderas, hasta que los vientos -macho y hembra- y los pumas consuman el "rapto" de Millapi:

11 Rituales de raspaje, limpieza o borradura de los sacramentos católicos mediante una acción simbólica, fueron algunas de las prácticas por las que fueron acusados de brujería y llevado a juicio en 1880 decenas de pu machi williche en el sector de la Isla Grande de Chiloé. El caso, conocido como "Juicio a los Brujos de la Recta Provincia" o a los "Médicos de la Tierra", cuenta con abundante bibliografía legal y antropológica sobre los conflictos entre derecho positivo y códigos consuetudinarios.

12 Gargalas y digüeñes son hongos comestibles y el kolkopío es la planta de la conocida flor roja de copihue. Es originaria de la selva valdiviana, en las cordilleras de la Costa y de los Andes, al sur de Chile. La raíz se emplea contra las enfermedades venéreas, la gota y el reumatismo.
"Quelwe

puigua macho puigua hembra

mazorcales

desmenuzaron la lumbre de tus caderas

Mercedes Millapan.

Te había llagado el rocío gargalas

digüene

kolkopío

puigua cuando te llevaron tayilcar

fue un aliento

el rapto del pangi" (p. 33)

La acción de "tayilcar" es cantar tayül, canto sagrado de antiguos linajes, efectuado por una machi (en este caso Millapan). Para concluir este trabajo de traducción cultural debemos hacer visible el doble linaje totémico del apellido Milla-pan (milla: oro o dorado; y pan: apócope de pangui, puma cordillerano), es decir, Millapan: puma del sol, o puma dorado. Por tanto, la hechicera Mercedes Millapan aquí es raptada por "su" pangui, "animal espiritual" de su propio linaje totémico, que la une a lo trascendente a través del intercambio del aliento. Millapan, entonces: machi raptada por su propio pullü, poseída en éxtasis; un cuerpo cosmo-biótico ${ }^{13}$ enlazado a sus antepasados, "danzando" en ese vínculo. Este es el tipo de acción molecular del que habla la micropolítica de Deleuze y Guattari (2002:135): múltiples movimientos que desplazan lo emplazado, líneas de fuga que alteran las codificaciones molares -y morales- del binarismo de género, una corporalidad que inscribe procederes contra-culturales desarraigando la lógica binaria opositiva y las naturalizaciones de la ritualidad cristiana.

La interacción de Mercedes Millapán y Filipa Huenuleo en el conjunto de la obra restituye las relaciones de tipo generacional y complementaria de la deidad Ngenechen: Wenü Ülcha (joven mujer del cielo) y Wenü Kushe (anciana del cielo); relaciones de juventud y vejez pero también de erotismo y muerte, fertilidad y guerra. Millapan no sufre el desalojo de Filipa, sus prácticas corporales "moleculares y hetero-genéricas", en términos deleuzianos, se desplazan de la dentellada molar, de la "hostia".

Por esta multiplicidad de sentidos que no se dejan emplazar es que creemos que la acción poética de Paredes Pinda se transforma en un modo de producción de subjetividades disidentes; un borde que trabaja en la mordedura del españolmapuzungun desregulando, de forma ritual y estética, las molaridades binarias excluyentes, poniendo a fluir incluso las propias contradicciones.

Una comprensión más amplia de estas poéticas no debe descartar sus vínculos con otras "formaciones discursivas" del mundo político mapuche en el histórico devenir

13 Es un concepto en desarrollo en el contexto de estas investigaciones. Pensamos provisoriamente que esa función de machi como cuerpo-borde de articulación o fluidez entre una multiplicidad que reúne naturaleza y cultura, puede entenderse como una relación cosmo- biótica que confronta las producciones hegemónicas de bio-poder.

Revista Internacional de Culturas y Literaturas, abril 2015 
de sus resistencias ante los intentos de asimilación plena o los multiculturalismos que pregonan "la tolerancia" desde un humanismo posmoderno que no está dispuesto a ceder sin más su situación de saber- poder colonial.

\section{CONSIDERACIONES FINALES}

Que la realidad del género sea performativa significa,

muy sencillamente, que es real sólo en la medida en que es actuada.

Butler (1998: 309)

La perspectiva fenomenológica radical de Judith Butler respecto de la doctrina de los actos constitutivos de la subjetividad, la lleva afirmar que "la verdad o falsedad del género son sólo socialmente forzadas y en ningún sentido ontológicamente necesitadas" (1998: 311), sino más bien una actuación cultural que se constituye en creencia e instituye normativas sociales y punitivas para aquellas subjetividades o cuerpos que se salen del paradigma.

A la fuerza pragmática de esos actos constitutivos e instituyentes Butler contrapone el develamiento de que allí no hay esencias inmodificables sino una "ontología de los gerundios" (1994: 314): cuerpos, lenguajes, subjetividades que están continuamente siendo, en una incesante materialización de posibilidades. Encarnaciones de género que si bien están histórica y socialmente condicionadas también están abiertas al cambio, justamente por su carácter performativo que en su devenir puede presentar u oponer realizaciones divergentes a la hetero-norma, como es el caso de las prácticas de machi:

\section{Los machi weye de género dual combinan ambos atributos, cualidades y
características reche masculinos y femeninos dinámicamente. Como no-hombres los weye participaban de lo femenino, aunque también conservaban algunas prerrogativas masculinas $y$, en ciertas ocasiones compartían un género con los hombres. Sus identidades de género están mejor explicadas por los avances recientes en la teoría de género donde el sexo no determina el género y, de hecho no guarda necesariamente ninguna relación con el género. (Bacigalupo, 2010: 39)}

La poesía de la machi (y académica) Adriana Paredes Pinda pone en evidencia otras posibilidades históricas y culturales de actuación corporal que han sido violentadas por la colonialidad. Como ya vimos, se trata de una poesía que políticamente reconfigura e instala imaginarios estéticos desde una episteme divergente (entiéndase esto como un conjunto de conocimientos y prácticas culturales basados en un ethos mapuche de pensamiento dual y complementario que implica una idea histórica diferente de los cuerpos y las relaciones de género). El análisis y comprensión transcultural que aquí presentamos está ligado a esa invitación de Butler a no renunciar "al poder de ampliar el campo cultural corporal con performances subversivas de diversas clases" (1994: 314).
El concepto de género, mayoritariamente analizado, cuestionado y deconstruido desde dentro del mismo sistema de oposiciones binarias de la maquinaria heterosexual -me refiero al feminismo histórico y luego los estudios trans, homo, inter, bi y otros desplazamientos críticos ligados a la hetero-norma-, encuentran un límite ontológico a ese binarismo en el pensamiento de Butler, en el pensamiento queer o en el Manifiesto Contrasexual (2011) de Beatriz Preciado, al develar al sistema de sexo- género como un sistema de escritura sobre los cuerpos, como tecnología biopolítica de producción de feminidad y masculinidad "que opera por división y fragmentación del cuerpo: recorta órganos y genera zonas de alta intensidad sensitiva y motriz (visual, táctil, olfativa) que después identifica como centros naturales y anatómicos de la diferencia sexual" (Preciado, 2011: 17)

Por lo tanto sostendremos que ese límite ontológico del género binario y la heteronorma, así como sus ficciones coactivas, productoras de sexualidad sobre los cuerpos y subjetividades, también deben ser leídos desde la diferencia cultural; revelando, además, el carácter colonial de esos actos constitutivos.

La perspectiva decolonial demuestra que esas prácticas y tecnologías de sexo- género binario excluyentes, enlazadas a otras prácticas e instituciones de dominio colonialracial, han producido históricamente roturas, desgarros epistémico-corporales en otras culturas y sujetos con memorias y prácticas que no cuajan en la hetero-norma. Las prácticas rituales de machi en la poesía de Paredes Pinda no sólo trasgreden las bipolaridades excluyentes del género, también cuestionan la racionalidad moderna que separó al cuerpo como objeto/naturaleza a dominar, desalojándolo de sus capacidades y derivas cognitivas.

Por otra parte, creemos que la perspectiva decolonial especialmente focalizada en la categoría de "etnicidad" se revelaría poco suficiente sin la variable crítica de los estudios de sexo-género para comprender las prácticas y actos constitutivos que hicieron -y aún hacen- posible la colonialidad del saber y del ser en nuestras culturas del sur.

\section{Referencias bibliográficas}

Bacigalupo, A. M., La voz del kultrun en la modernidad. Tradición y cambio en la terapéutica de siete machi mapuche. Santiago, Universidad Católica de Chile. 2001.

----,. “La lucha por la masculinidad de Machi. Políticas coloniales de Género, Sexualidad y Poder en el sur de Chile". Revista de Historia Indígena, 6 (2003).

----,. “Rituales de género para el orden cósmico: las luchas chamánicas por el orden cósmico y la totalidad. Revista Scripta Ethnológica, 26 (2004). 
----, "Relaciones de género ritual: Parentesco, matrimonio, dominio y modalidades de condición de persona para los chamanes mapuche". Revista Austral de Ciencias Sociales. 18 (2010), pp. 83-106.

Butler, J., “Actos performativos y constitución del género: Un ensayo sobre fenomenología y teoría feminista". Revista Debate Feminista, 18 (1998), pp. 296-314.

Catrileo, M., La lengua mapuche en el Siglo XXI, Valdivia, Universidad Austral de Chile. 2010.

Carrasco, I., “Poetas mapuche contemporáneos”, en Revista Pentukun. 10 (2000).

Castro-Gómez, S., “Ciencias Sociales, violencia epistémica y el problema de la invención del otro", en Lander, Edgardo, compilador: Colonialidad del saber, eurocentrismo y ciencias sociales, Buenos Aires. Editorial CLACSO, 2003.

Connell, R., 1997: “La organización social de la masculinidad” en Masculinidad/es. Poder y crisis. 24 (1997), pp. 31-48.

Deleuze, G. y Guattari, F., Mil mesetas. Capitalismo y esquizofrenia, Valencia, Pre Textos, 2002.

Foucault, M., La arqueología del saber, México, Siglo Veintiuno, 1979.

----, Un diálogo sobre el poder y otras conversaciones, Madrid, Alianza Editorial, 2000.

----, Historia de la Sexualidad I, La voluntad de saber, México, Siglo XXI Editores, 1998.

Guattari, F., Caosmosis. Buenos Aires, Manantial, 1996.

Mansilla Torres, S., Culturas en crisis: versiones y perversiones sobre nosotros y los otros. Valdivia, El Kultrún, 2002.

Moraga, F., "Adriana Pinda y el habla escrita de la ajenidad: Relámpago", Revista Alpha, 23. (2009).

Paredes Pinda, A., Üi, Santiago, LOM, 2005

Preciado, B., Manifiesto Contrasexual, Barcelona Anagrama, 2011.

Rodríguez Monarca, C., “Weupüfes y machis: canon, género y escritura en la poesía mapuche actual". Revista de Estudios Filológicos, 40 (2005).

Quijano, A., "Colonialidad del poder, eurocentrismo y América Latina”, en Lander, Edgardo, compilador, Colonialidad del saber: eurocentrismo y ciencias sociales, Buenos Aires, CLACSO, 2003.

Spíndola, J., "Poesía mapuche y fronteras culturales", Revista Confines -Arte y cultura desde la Patagonia-. Julio/Agosto 2009. Internet. 31-07-13.

http://www.confinesdigital.com/conf20/poesia-mapuche-y-fronteras-culturales.html 